\title{
Acyclovir Loaded Solid Lipid Nanoparticulate Gel for Ocular Delivery: Optimization by using Factorial Design
}

\author{
Subhabrota Majumdar', Suryakanta Swain ${ }^{2,3, *}$, Muddana Eswara Bhanoji Rao', Puja Chakraborty ${ }^{1}$, \\ Sabya Sachi Das ${ }^{4}$
}

${ }^{1}$ Calcutta Institute of Pharmaceutical Technology and AHS, Banitabla, Uluberia, Howrah, West Bengal, INDIA.

${ }^{2}$ School of Health Sciences, Department of Pharmaceutical Sciences, The Assam Kaziranga University, Jorhat, Assam-785006, INDIA ${ }^{3}$ Southern Institute of Medical Sciences, College of Pharmacy, Department of Pharmaceutics, SIMS Group of Institutions, Mangaldas Nagar, Vijayawada Road, Guntur, Andhra Pradesh, INDIA.

${ }^{4}$ Department of Pharmaceutical Sciences and Technology, Birla Institute of Technology, Mesra, Ranchi, Jharkhand, INDIA.

\begin{abstract}
Background: Acyclovir is a potent antiviral agent primarily used to treat viral infection in the eye, signified as Herpes Simplex Keratitis caused by Herpes Simplex Virus-1. But its applications are limited because of its poor oral bioavailability and permeability caused by significant first-pass metabolism. Objectives: The study is to design the formulation, optimization, in-vitro, ex-vivo and in-vivo characterization of solid lipid nanoparticulate gel (SLNG) of acyclovir and inspect their possibility in ocular applications. Methods: SLNG of acyclovir was prepared by hot homogenization technique and optimized by $2^{3}$ factorial design and evaluated for in-vitro physicochemical characteristics and in-vivo pharmacokinetic study. Response surface methodology estimations and plots for optimization to obtain optimum values for response variables based on desirability criteria was performed using Design-Expert software. Results: The optimized formulation showed a particle size of $193.57 \pm 1.14 \mathrm{~nm}$, zeta potential of $35 \pm 1.98 \mathrm{mv}$, drug entrapment efficiency of $82 \pm 1.59 \%$ and drug loading efficiency of $54.10 \pm 0.79 \%$, indicating good physical stability. The transcorneal study showed a significant increase in drug permeation across the cornea as compared with the control. The drug release kinetics of the prepared formulations was best fitted to the first-order kinetic model. In-vivo pharmacokinetic studies revealed a significant enhancement in the drug level in the blood plasma of the optimized formulation as compared to the pure drug suspension. Conclusion: The acyclovir-loaded SLN gel was successfully developed, optimized, evaluated and exhibited enhanced drug permeation as well as systemic bioavailability through excised corneas. Thus, SLNG acts as a favorable approach for ocular applications of acyclovir.
\end{abstract}

Key words: Acyclovir, Hot homogenization, Factorial design, Drug entrapment efficiency, Transcorneal study, Pharmacokinetic study.

\section{INTRODUCTION}

The current pharmaceutical research for designing and developing a Solid Lipid Nanoparticles (SLNs) drug delivery system faces significant challenges and limitations. ${ }^{1}$ Solid lipid nanoparticles have substantial advantages as colloidal drug delivery systems $(50-1000 \mathrm{~nm})$, increased protection of encapsulated drugs against chemical degradation and enzymatic metabolism and targeting pharmacologically active drug moieties at the targeted sites with accurate dosing and time. ${ }^{2}$ Moreover, the presence of surfactants in SLNs formulations and their small size gives an excellent opportunity to increase permeability, enhance drug bioavailability and use various administration routes such as parenteral, oral, ocular, dermal and pulmonary, etc. ${ }^{3,4}$

The conventional topical delivery systems of drugs through ocular routes with some
Submission Date: 22-04-2020; Revision Date: 26-07-2020; Accepted Date: 23-11-2020

DOI: 10.5530/ijper.55.1s.43 Correspondence: Dr. Suryakanta Swain School of Health Sciences, Department of Pharmaceutical Sciences, The Assam Kaziranga University, Jorhat, Assam-785006, INDIA. Phone no: +91-7702247710 Email id: swain_suryakant@ yahoo.co.in

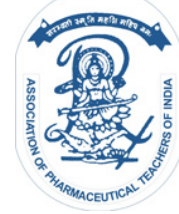

www.ijper.org 
significant issues such as quick and severe pre-corneal loss are affected due to the drainage and extreme tear fluid turnover. The ultimate objective is to improve the therapeutic consequences for effective treatment or management of various ocular diseases by increasing the cornea's drug penetration, with significant efforts in ophthalmic delivery. In this view, specific potential approaches associated with colloidal drug delivery systems including such as liposomal systems, biodegradable or polymeric nanoparticles, and nanocapsules. ${ }^{5-9}$

Hot homogenization is a useful method carried out at a temperature beyond the melting for point of the lipid and that is why it is considered the homogenization of an emulsion. Higher temperature results in smaller particle size, thereby decreases the viscosity of the inner phase. Hot homogenization technique followed by sonication used was in the preparation of SLN. ${ }^{10,11}$

Moreover, Response Surface Methodology (RSM) has proved to be one of the most efficient tools used for the optimization and development of nanoparticulate based drug delivery systems. In RSM, various steps are involved, including experimental design, regression analysis, constraint optimization and validation. The methodology is compatible with the exploration of quadratic response surfaces and construction of secondorder polynomial models. ${ }^{12}$

Acyclovir is a BSC class III (high solubility and low permeability) potent antiviral agent used to treat mainly viral eye infections such as Herpes Simplex Keratitis, Keratouveitis and anterior uveitis by killing or inhibiting the growth of the virus on the corneal surface. It has limited applications due to poor bioavailability (10$30 \%)$, low lipophilicity and less intrinsic solubility (1.2 $\mathrm{mg} / \mathrm{mL}$ ). The other important parameter of such drug is low partition coefficient (P-octanol) of $\sim 0.023$ may reflect the low membrane permeability and dissociation constants (Pka) of 2.34 and 9.23 caused by ample firstpass metabolism and also a high dose of the drug is to achieve the therapeutic drug level due to its short halflife $(1.5-3.5 \mathrm{~h}){ }^{13}$

The literature study observed that limited research work reported on the formulation of controlled ocular delivery of acyclovir through the rate-controlling ocular insert of eudragit and acyclovir-loaded chitosan nanoparticles. Therefore, the rationale for the preparation of SLN is an efficient carrier for the ocular delivery of acyclovir. It may help decrease the drug dose and maintain the drug in the systemic circulation for a prolonged period. This sentence may be included in the conclusion part.

\section{MATERIALS AND METHODS}

\section{Materials}

Acyclovir was gifted by M/s Klar Sehen Pvt. Ltd. (CAS Reg. No: 59277-89-3 and mol. Wt. 225.21g/mol., Mumbai, India). In contrast, various materials such as chitosan (Degree of de-acetylation of $85 \%$ with CAS Reg. No: 9012-76-4 and mol. Wt.-3800-20,000 daltons) gifted by M/s Sigma Aldrich Co, USA. Soya-lecithin and stearic acid gifted by $\mathrm{M} / \mathrm{s}$ Abitec (CAS Reg. No: 8002-43-5 and Mol. Wt. $677.932541 \mathrm{gm} / \mathrm{mol}$, Janesville, USA). The surfactant and gelling agent gifted by $\mathrm{M} / \mathrm{s}$ Sigma Chemicals Co. Ltd. and M/s SD Fine Chemicals, Mumbai, India. All other solvents and reagents used for the research work were of analytical grade.

\section{Methods}

\section{Preparation of the oil phase}

The solid lipid nanoparticles of acyclovir were prepared using the hot homogenization technique, as shown in Table 1. Briefly, the required quantity of the drug (Acyclovir), stearic acid and soya-lecithin dissolved in a $5 \mathrm{ml}$ organic mixture of methanol and chloroform (1:1), appropriately mixed and then were transferred into the sterilized round bottom flask (RBF). The round bottom flask was then attached to the rotary evaporator (IKA RV-10 digital V, Karnataka, India) for the lipid layer formation. The obtained drug embedded lipid layer was further heated to $80^{\circ} \mathrm{C}$ temperature and homogenized for 10 min using a high-speed homogenizer (IKA T-25 digital ULTRA-TURRAX ${ }^{\circledR}$, Karnataka, India) with $5000 \mathrm{rpm}$ speed for the formation of the hot oil phase.

\section{Preparation of aqueous phase}

The required quantity of chitosan and poloxamer-188 are accurately weighed in a beaker and to this deionized water $(100 \mathrm{ml})$ containing tween 80 as a surfactant mixed at $70^{\circ} \mathrm{C}$ temperature and homogenized for 10 min using a high-speed Homogenizer (IKA T-25 digital ULTRATURRAX®, Karnataka, India) at a speed of $5000 \mathrm{rpm}$ for the formation of the hot aqueous phase.

\section{Preparation of acyclovir-loaded SLN}

The prepared aqueous phase slowly mixed with the prepared hot oil phase. It was then homogenized for $30 \mathrm{~min}$ at a homogenization speed of $5000 \mathrm{rpm}$ using a high-speed Homogenizer (IKA T-25 digital ULTRATURRAX ${ }^{\circledR}$, Karnataka, India) to obtain a coarse hot oil in water emulsion $(\mathrm{O} / \mathrm{W})$. Further, the system was ultra-sonicated for $10 \mathrm{~min}$ to achieve acyclovir loaded SLNs. The prepared SLN were allowed to cool at room temperature and was then lyophilized (Decibel Digital 
Table 1: Formulation design of solid lipid nanoparticles prepared by hot homogenization technique.

\begin{tabular}{|c|c|c|c|c|c|c|c|}
\hline $\begin{array}{c}\text { Formulation } \\
\text { code }\end{array}$ & Drug (\%w/v) & $\begin{array}{c}\text { Stearic acid } \\
(\%)\end{array}$ & $\begin{array}{c}\text { Soya-lecithin } \\
(\%)\end{array}$ & $\begin{array}{c}\text { Chitosan } \\
(\% \mathbf{\%} / \mathbf{)})\end{array}$ & Tween 80 (\%) & $\begin{array}{c}\text { Poloxamer } \\
\mathbf{1 8 8}(\%)\end{array}$ & $\begin{array}{c}\text { Carbopol } \\
\mathbf{9 4 0 P}(\% \mathbf{\%} / \mathbf{v})\end{array}$ \\
\hline F1 & 3 & 9 & 9 & 3 & 1 & 2 & 2 \\
\hline F2 & 3 & 27 & 9 & 2 & 1 & 2 & 2 \\
\hline F3 & 3 & 27 & 9 & 3 & 1 & 2 & 2 \\
\hline F4 & 3 & 27 & 9 & 2.5 & 1 & 2 & 2 \\
\hline F5 & 3 & 9 & 9 & 2 & 1 & 2 & 2 \\
\hline F6 & 3 & 18 & 9 & 3 & 1 & 2 & 2 \\
\hline F7 & 3 & 18 & 9 & 2.5 & 1 & 2 & 2 \\
\hline F8 & 3 & 9 & 9 & 2.5 & 1 & 2 & 2 \\
\hline F9 & 3 & 18 & 9 & 2 & 1 & 2 & 2 \\
\hline
\end{tabular}

\begin{tabular}{|c|c|c|c|c|c|c|c|c|c|c|}
\hline \multirow[b]{2}{*}{$\begin{array}{l}\text { Formulation } \\
\text { code }\end{array}$} & \multicolumn{2}{|c|}{$\begin{array}{l}\text { Independent variables } \\
\text { with coded values }\end{array}$} & \multicolumn{2}{|c|}{$\begin{array}{c}\text { Independent } \\
\text { variables with } \\
\text { original values }\end{array}$} & \multirow[b]{2}{*}{$\begin{array}{l}\text { Selected } \\
\text { Runs }\end{array}$} & \multirow{2}{*}{$\begin{array}{l}\text { Stearic } \\
\text { acid: } \\
\text { Soya- } \\
\text { lecithin } \\
\text { (mg) }\end{array}$} & \multirow[b]{2}{*}{$\begin{array}{l}\% \text { w/v of } \\
\text { chitosan }\end{array}$} & \multirow{2}{*}{$\begin{array}{l}\text { Particle } \\
\text { size (nm) } \\
\text { (Y1) }\end{array}$} & \multirow{2}{*}{$\begin{array}{l}\text { Drug } \\
\text { release } \\
\text { (\%) } \\
\text { (Y2) }\end{array}$} & \multirow{2}{*}{$\begin{array}{c}\text { Drug } \\
\text { entrapment } \\
\text { efficiency } \\
\text { (\%) } \\
\text { (Y3) }\end{array}$} \\
\hline & $\begin{array}{c}\text { Stearic acid: } \\
\text { Soya-lecithin } \\
\text { (X1) }\end{array}$ & $\begin{array}{l}\% \text { w/v of } \\
\text { chitosan } \\
\text { (X2) }\end{array}$ & $\begin{array}{l}\text { Stearic } \\
\text { acid: } \\
\text { Soya- } \\
\text { lecithin } \\
\text { (X1) }\end{array}$ & $\begin{array}{l}\% \text { w/v of } \\
\text { chitosan } \\
\text { (X2) }\end{array}$ & & & & & & \\
\hline F1 & -1 & 1 & $1: 3$ & 3 & 1 & 18 & 2 & 91.28 & 46.21 & 72.04 \\
\hline F2 & 1 & -1 & $3: 3$ & 2 & 2 & 18 & 2.5 & 133.03 & 48.58 & 74 \\
\hline F3 & 1 & 1 & $3: 3$ & 3 & 3 & 18 & 3 & 171 & 49.27 & 80.2 \\
\hline F4 & 1 & 0 & $3: 3$ & 2.5 & 4 & 27 & 2.5 & 158.24 & 48.74 & 73.23 \\
\hline F5 & -1 & -1 & $1: 3$ & 2 & 5 & 11.63 & 2.85 & 193.57 & 50.29 & 82 \\
\hline F6 & 0 & 1 & $2: 3$ & 3 & 6 & 24.36 & 2.85 & 207.1 & 49.84 & 77.05 \\
\hline F7 & 0 & 0 & $2: 3$ & 2.5 & 7 & 11.63 & 2.14 & 86 & 46.63 & 70.93 \\
\hline F8 & -1 & 0 & $1: 3$ & 2.5 & 8 & 9 & 2.5 & 108.92 & 48.92 & 74.16 \\
\hline F9 & 0 & -1 & $2: 3$ & 2 & 9 & 24.36 & 2.14 & 95.4 & 45.89 & 66.17 \\
\hline
\end{tabular}

Stearic acid: Soya-lecithin $\left(\mathrm{X}_{1}\right)$-1 level indicates 1:3; o level indicates 2:3 and +1 level indicates 3:3 and \% w/v of chitosan ( $\left.\mathrm{X}_{2}\right)-1$ level indicates 2;

o level indicates 2.5 and +1 level indicates 3

Technologies, India) for $36 \mathrm{~h}$ at $-60^{\circ} \mathrm{C}$ temperature, with pressure below 15 Pascal.

\section{Preparation of acyclovir-loaded SLNG}

The Acyclovir-loaded SLNG prepared by taking carbopol-940P $(2 \% \mathrm{w} / v)$ and dispersed into the hot ultrapure water and to this formed dispersion, glycerol $(10 \% \mathrm{w} / \mathrm{v})$ was added and allowed to swell overnight. Further, the formed Acyclovir loaded SLN (The dose of drug-taking equivalent SLN dispersion containing $3 \% \mathrm{w} / \mathrm{v}$ of Acyclovir) was added to the hydrogel system and mixed well using a high-speed stirrer at a speed of $1000 \mathrm{rpm}$ for $5 \mathrm{~min}$, with the $\mathrm{pH}$ value adjusted to 7 (Drop wise addition of triethanolamine). This lead to the preparation of the Acyclovir loaded SLN gel and further stored in a suitable container.

\section{Formulation optimization by statistical design}

A $2^{3}$ factorial design was employed for the systematic optimization of the critical attributes and performed with the help of Design-Expert software version 9.0.1 (M/s Stat-Ease, Minneapolis, USA). For the formulation, the amount of stearic acid: soya lecithin (X1) based on the ratio of stearic acid to soya lecithin (X1) taken in proportion with $9,18,27 \%$ of stearic acid and $9 \%$ soya lecithin and $\% \mathrm{w} / v$ of chitosan (X2) selected as independent variables and $\mathrm{Y} 1=$ particle size, $\mathrm{Y} 2=\%$ drug release rate at 4 hours and $\mathrm{Y} 3=\mathrm{EE}(\%)$ chosen as dependent variables. Independent variables with coded and original values shown in Table $2 .{ }^{14}$

\section{Data analysis and validation of the optimization model}

Various response surface method computations for the present optimization study performed using Design Expert ${ }^{\circledR}$ software version $9.0 .1 \mathrm{(M} / \mathrm{s}$ StatEase, Minneapolis, USA). Furthermore, polynomial models comprising the interaction and quadratic terms produced for all the response variables using multiple linear regression analysis (MLRA) approach. The 
general form of the MLRA model signified as the following equation 1 :

$$
\begin{aligned}
\mathrm{Y}= & \beta 0+\beta 1 \mathrm{X} 1+\beta 2 \mathrm{X} 2+\beta 3 \mathrm{X} 1 \mathrm{X} 2+\beta 4 \mathrm{X} 12+ \\
& \beta 5 \mathrm{X} 22+\beta 6 \mathrm{X} 1 \mathrm{X} 22+\beta 7 \mathrm{X} 12 \mathrm{X} 2
\end{aligned}
$$

Here, $\beta 0$ is the intercept value that signifies the arithmetic average of all the quantitative outcomes of 9 runs; $\beta 1$ to $\beta 7$ are the coefficients calculated from the experimental response values of $\mathrm{Y}, \mathrm{X} 1$ and $\mathrm{X} 2$ are the coded levels of the independent variable (s). The terms $\mathrm{X} 1 \mathrm{X} 2$ and X12 represent the interface and quadratic expressions, respectively. The polynomials' statistical rationality was recognized based on the ANOVA modeling present in the Design Expert Software. Further, the two-dimensional (2D) contour plot and three-dimensional (3D) response surface plot was established based on the polynomial model's functions. These plots have proved to be worthy of observing the effects of interaction between the factors and responses. To validate the chosen experimental design and polynomial equations, eight optimum checkpoints selected from the grid search and executed experimental domain. Finally, the formulations conforming to these checkpoints were developed and evaluated for different response attributes. Consequently, the resulting experimental data of the response attributes were quantitatively compared with their predicted values. Moreover, the linear regression plots between the predicted and observed benefits of the response attribute plotted using MS-Excel, imposing the line through the origin. ${ }^{15,16}$

\section{Mathematical modelling for RSM optimization}

Mathematical relationships were written in the form of the polynomial equations for the measured responses, including particle size $(\mathrm{nm})$, drug release $(\%)$ at $4 \mathrm{~h}$ and EE (\%) obtained from the stat ease software. The polynomial equations relating the various responses and independent variables is given below:

$$
\begin{aligned}
\mathrm{Y} 1(\text { Particle size in } \mathrm{nm})= & 138.282+11.5849 \mathrm{X} 1+ \\
& 41.5014 \mathrm{X} 2
\end{aligned}
$$

Y2 $(\%$ Drug release at $4 \mathrm{~h})=48.2633-0.18057 \mathrm{X} 1+$

$$
\text { 1.49219X2 }
$$

$\mathrm{Y} 3(\% \mathrm{EE})=74.42-1.37815 \mathrm{X} 1+4.18625 \mathrm{X} 2$

The quantitative consequences of the independent variables and their interface on the responses are denoted through the above equations. For assessment of the significance of the model, the analysis of variance (ANOVA) was envisioned as per design expert software.
Using a 5\% significance level, a model is considered significant if value of $p<0.05 .{ }^{17}$

\section{Characterization and evaluation of acyclovir- loaded SLN}

\section{Fourier transform infrared spectroscopy}

FT-IR (Shimadzu IR Affinity-I instrument, Tokyo, Japan) was used for carrying out the drug-excipient compatibility study between the drug and the excipients. The pellets were prepared by gently mixing of $1 \mathrm{mg}$ sample with $200 \mathrm{mg}$ potassium bromide at high compaction pressure. The scanning range was 450 to $4000 \mathrm{~cm}^{-1}$ and the revolution was $4 \mathrm{~cm}^{-1}$. It was performed to observe any significant interactions and shifting of the major peaks of the drug in the spectrum of the physical mixture of drug and the selected excipients. ${ }^{18}$

\section{Differential scanning calorimetry}

Differential scanning calorimetry analysis performed with differential scanning calorimeter (Shimadzu DSC-60 instrument, Tokyo, Japan). For the measurement, $10 \mathrm{mg}$ of the sample accurately weighed in a standard aluminium pan thematically sealed and heated at a rate of $5^{\circ} \mathrm{C}$ per min- 1 in a 30 to $300^{\circ} \mathrm{C}$ temperature under a nitrogen flow of $40 \mathrm{ml} / \mathrm{min}$, the empty pan is considered as reference. DSC scans performed with heating and cooling parameters at a rate of $5^{\circ} \mathrm{C}$ under liquid nitrogen. Enthalpies calculated using the mettle star software. ${ }^{19}$

\section{Particle size and zeta potential analysis}

The particle size and polydispersibility index (PDI) of SLN was measured by photon correlation spectroscopy (PCS, Nano ZS90 Zetasizer, Malvern Instruments, $\mathrm{UK}$ ) at $25^{\circ} \mathrm{C}$ under a static angle of $90^{\circ}$ in polystyrene cuvettes. The measurements were attained through a He-Ne laser with a wavelength of $\lambda_{\text {max }} 633 \mathrm{~nm}$. Also, the zeta potential was calculated for all the formulations using the Nano ZS90 zeta sizer. ${ }^{20}$

\section{Drug entrapment efficiency and loading efficiency}

Entrapment efficiency (EE \%) was determined by the dialysis method. The dialysis tubing cellulose membrane (Molecular weight cut-off $=12,000 \mathrm{k} \mathrm{Da}$, average flat width $25 \mathrm{~mm}$ (1.0 in.), (Sigma-Aldrich, USA) was hydrated in PBS overnight. Entrapment efficiency was determined by taking equivalent SLN dispersion containing $3 \% \mathrm{w} / \mathrm{v}$ of acyclovir. The formulation was centrifuged at $2000 \mathrm{rpm}$ for $1 \mathrm{~h}$ to collect superannuated liquid, filtered, suitable dilution made with fresh phosphate buffer $\mathrm{pH}$ 7.4. Subsequently, absorbance was measured at $\lambda_{\text {max }} 255.5 \mathrm{~nm}$ using a UV-Visible 
spectrometer (Shimadzu-1700, Tokyo, Japan). Theoretically, the percent entrapment efficiency (\% EE) of the drug is the ratio of the experimentally calculated drug content with the actual or theoretical amount of the drug used to prepare SLN. It is calculated by using as equation $5 .^{21}$

$$
\begin{aligned}
& \text { Amount of drug entrapped } \\
& \% \mathrm{EE} \text { of drug }=\frac{\text { in particles }}{\text { Total amount of drug added }} \times 100 \\
& \text { during preparation }
\end{aligned}
$$

Drug loading indicates the percent $(\%)$ weight of the encapsulated drug to the weight of the SLNs. Loading efficiency $(\%$ LE) depends upon the blend of drugpolymer and the method adopted and calculated as per equation $6 .^{22}$

$$
\% \text { LE of drug }=\frac{\mathrm{Qn}}{\mathrm{Wn}} \times 100
$$

Where Qn is the amount of drug present in SLN and Wn is the weight of SLN.

\section{Stability study}

The acyclovir loaded SLN were stored at $2-8^{\circ} \mathrm{C}$ for three months and their physical and chemical stability were evaluated for their clarity, particle size and zeta potential. The acyclovir loaded SLN were centrifuged for $30 \mathrm{~min}$ at $15,000 \mathrm{rpm}$ in the centrifuge tests to carry out the stability testing. ${ }^{23}$

\section{Characterization of acyclovir-loaded SLNG Physical Examination}

The prepared gel was macroscopically examined for visual appearance, colour and clarity, etc. Clarity evaluated by visual observation of the solutions using a black and white background in a well-lit cabinet. Digital $\mathrm{pH}$ meter was used for the analysis of the $\mathrm{pH}$ of the gel. ${ }^{24}$

\section{Drug content}

$1 \mathrm{gm}$ of SLNG was withdrawn from the container and was dissolved in methanol $(5 \mathrm{ml})$ and the volume was made up to $100 \mathrm{ml}$ using distilled water. After suitable dilutions, the absorbance was measured by UV spectrophotometer (Shimadzu, Tokyo, Japan) against a blank (Phosphate buffer $\mathrm{pH} 7.4$ ) at $\lambda_{\text {max }} 255.5 \mathrm{~nm}$ and then the drug content was calculated. ${ }^{24}$

\section{Trans-corneal in-vitro drug permeation study}

Franz diffusion cell was used for the in-vitro drug release study of the acyclovir-loaded SLNG (The dose of drug-taking equivalent SLN dispersion containing 3\% w/v of Acyclovir). The permeation of acyclovir across the corneal membrane study was conducted using the goat cornea. The optimized formulation was added in the donor compartment and freshly prepared simulated tear fluid was placed in the receptor compartment. Further, the goat cornea was placed in between the donor and a receptor compartment. The whole assembly should be assembled on the thermostatically controlled magnetic stirrer. The temperature of the medium was maintained at $37 \pm$ at $0.5^{\circ} \mathrm{C}$. The aliquots $(5 \mathrm{ml})$ were collected at periodic time intervals for up to $4 \mathrm{~h}$ in a microcentrifuge tube. They were quantified via the UV-Visible spectrophotometric method (Shimadzu-1700, Tokyo, Japan) against a blank (Phosphate buffer $\mathrm{pH}$ 7.4) at $\lambda_{\max } 255.5 \mathrm{~nm}^{25}$

\section{Sterility testing}

According to Indian Pharmacopoeia, the sterility testing of ophthalmic formulations is performed using a direct inoculation method. As per the technique, $2 \mathrm{ml}$ of liquid from test container was removed to test the liquid with a sterile pipette, or with a sterile syringe or a needle and was aseptically transferred to fluid thioglycollate medium $(20 \mathrm{ml})$ and soya bean-casein digest medium $(20 \mathrm{ml})$ separately and was appropriately mixed. The inoculated media was incubated for no less than 14 days at a temperature of 30 to $35^{\circ} \mathrm{C}$ in the case of fluid thioglycollate medium and 20 to $25^{\circ} \mathrm{C}$ in the soya beancasein digest medium. ${ }^{26}$

\section{Ocular irritation study}

The Draize irritancy test tested the ocular irritation proficiency of the ophthalmic formulation. According to this test, the amount of formulation applied to the eye (100ul) was given into the lower cul-de-sac of male rabbits and the observation of the different criteria was made at the desired time interval $1 \mathrm{~h}, 24 \mathrm{~h}, 48 \mathrm{~h}, 72 \mathrm{~h}$ and one week. The sterile formulation was infused twice a day for up to seven days and a cross-over study was carried out (Before the cross-over study, a 3-day washing period with saline was performed). Rabbits were observed periodically for redness, swelling and watering from the eyes. All experimental procedures were reviewed and permitted by the institutional animal ethical committee of Calcutta Institute of Pharmaceutical Technology and Allied Health Sciences, India, with registration number 2075/PO/Re/s/19/CPCSEA. ${ }^{27}$

\section{In-vivo pharmacokinetic study}

In-vivo pharmacokinetics were performed in male Wistar rats $(n=6)$ with a single dose under the fasting conditions. Further, the optimized SLNG (F5) and suspension of the pure drug were administered through feeding cannula, keeping the oral dose of $10 \mathrm{mg} / \mathrm{kg}$ body weight. The 
experimental process was reviewed and endorsed by the Institutional Animal Ethical Committee of Calcutta Institute of Pharmaceutical Technology and Allied Health Sciences, West Bengal, India, with registration number 2075/PO/Re/s/19/CPCSEA. After the dose administration, the blood samples were taken from the retro-orbital venous plexus puncture at a time interval of $0,1,3,6,12,24$ and $48 \mathrm{~h}$. About $0.5 \mathrm{ml}$ of blood samples were withdrawn from the Eppendorf tube and was led for centrifugation at $3000 \mathrm{rpm}$ for $30 \mathrm{~min}$. The plasma was transferred to another sterilized Eppendorf tube and was stored firmly at $-20^{\circ} \mathrm{C}$ until the analysis. Furthermore, the pharmacokinetic data analysis was performed with the help of the reported HPLC method and by the non-compartmental modeling approach. Various parameters such as peak plasma concentration $\left(\mathrm{C}_{\max }\right)$ and corresponding time $\left(\mathrm{T}_{\max }\right)$ and area under the curve (AUC) for all the samples were calculated. They were then statistically compared using ANOVA followed by post-hoc t-test at $5 \%$ level of significance. ${ }^{28}$

\section{Accelerated stability study}

The optimized formulation (F5) was kept in an ambient color vials and were sealed with aluminum foil for short-term accelerated stability studies for 3 months at $\left(40 \pm 2{ }^{\circ} \mathrm{C}\right.$ and $\left.75 \pm 5 \% \mathrm{RH}\right)$ as per the International Conference on the Harmonization States (ICH) Guidelines. The parameters such as clarity, particle size and zeta potential were evaluated and data are shown in Table $3{ }^{29}$

\section{RESULTS AND DISCUSSION}

\section{Preparation of acyclovir-loaded SLN and SLNG}

The purpose of the present study is to design, optimize and evaluate solid lipid nanoparticulate gel of acyclovir for ocular application to improve its permeability for the effective treatment of ophthalmic viral infections. Methanol and chloroform have been used as dissolving agents of the drug. Stearic acid and soya lecithin are used as lipid phase, chitosan used as polymer, poloxamer-188 and tween 80 used as aqueous phase (Surfactant) and carbopol 940 used as a gelling agent for formulating the gel. The entire formulations have been prepared by the hot homogenization technique, as shown in Table 1 and selected independent variables (X1, X2 and X3) with coded and original values and dependent variables (Y1, Y2 and Y3) obtained from runs chosen shown in Table 2.

\section{Characterization of acyclovir-loaded SLN}

\section{Fourier transform infrared spectroscopy}

The FT-IR study results indicated that there were no significant interactions between the drug and the polymer used to prepare the formulation. The FT-IR interpretation observed that the drug showed no alterations in its major peals, so the drug sample used was pure and stable. Moreover, the FT-IR interpretations of drug and selected polymers showed characteristics prominent peaks of intramolecular $-\mathrm{OH}$ bonding at $3518.16 \mathrm{~cm}^{-1}$, intermolecular -OH bonding at 3294.42 $\mathrm{cm}^{-1},-\mathrm{NH}$ at $3130.47 \mathrm{~cm}^{-1},-\mathrm{C}=\mathrm{C}$ at $2218.14 \mathrm{~cm}^{-1},-\mathrm{C}=0$ stretching at $1612.49 \mathrm{~cm}^{-1}$ and $-\mathrm{C}-\mathrm{N}$ stretching at 1388 . $75 \mathrm{~cm}^{-1}$ (Figure 1)..$^{18}$

\section{Differential scanning calorimetry}

The obtained DSC thermo grams for all the samples are summarized in Figure 2 and according to the thermo grams, acyclovir showed a sharp endothermic peak at $254.82^{\circ} \mathrm{C}$ analogous to the melting point of the pure drug. Though, as compared to a pure drug, there was a slight difference in the endothermic peak of the optimized formulation $\left(253.92^{\circ} \mathrm{C}\right)$. By contrast, no endothermic peak was seen for acyclovir in the thermo gram of the optimized SLN formulation. These results suggested that the entrapped drug in the SLN formulation was in the amorphous form. The drug has higher energy with increased surface area in the amorphous state with better solubility, dissolution and bioavailability compared with the crystalline form. ${ }^{19}$

\section{Particle size and zeta potential analysis}

The particle size values of all the formulations range from $86 \mathrm{~nm}$ to $207.10 \mathrm{~nm}$. The different acyclovir SLN formulation measured by photon correlation microscopy and it observed that all the formulations exhibited narrowest size distribution. Besides this, there was no significant difference in the distribution between acyclovir SLN and blank SLN. The zeta potential values of acyclovir-loaded SLNG formulations found to be in the range of $+32.83 \pm 3.07 \mathrm{mV}$ to $+42.7 \pm 1.12 \mathrm{mV}$ and shown in Table 3 . The zeta potential commonly used to characterize the surface charge property of prepared solid lipid nanoparticles. It reflects the electrical potential of SLN and is influence by the composition of the SLN and the medium dispersed. SLN with a zeta potential above (+/-) $30 \mathrm{mV}$ is stable in suspension, as the surface charge prevents aggregation of the particles. The zeta potential used to determine whether a charged active material is encapsulated within the center of the 


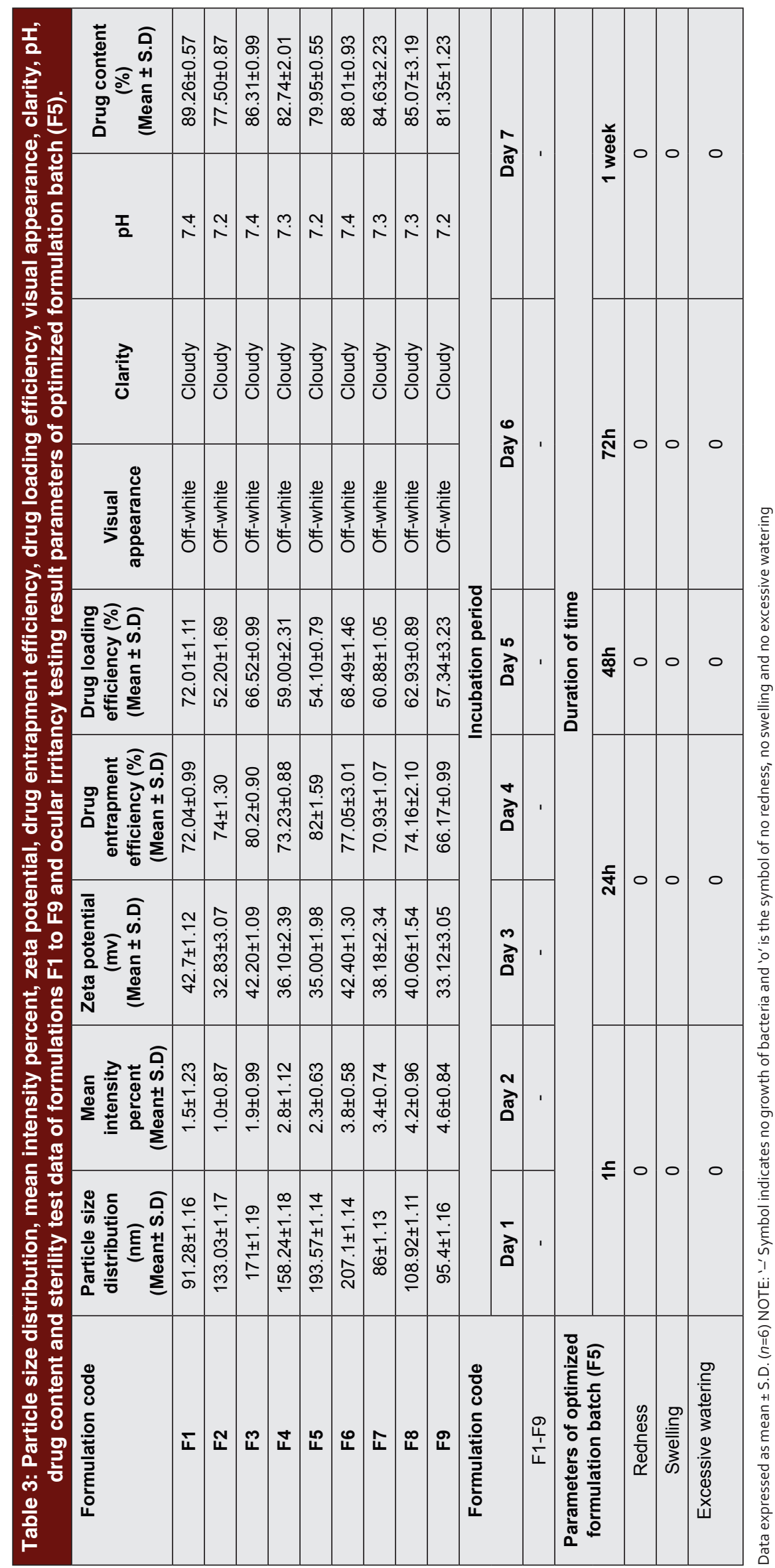



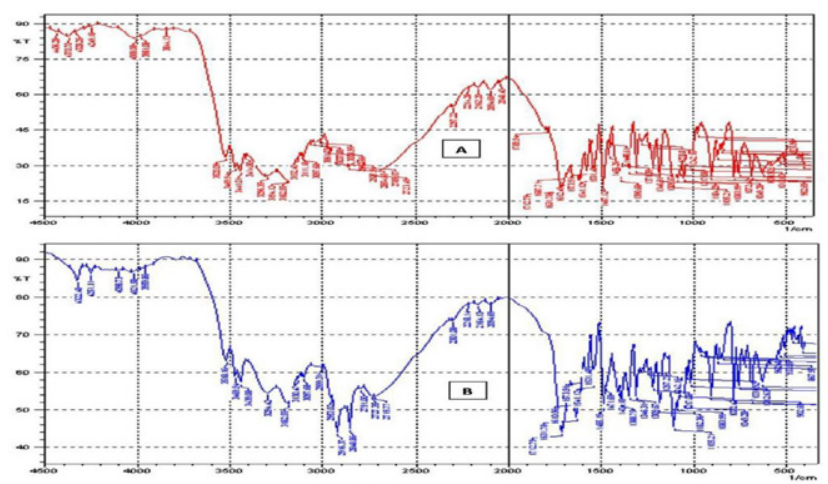

Figure 1: FT-IR spectra of the pure drug (Acyclovir) [A] and optimized formulation (F5) [B].

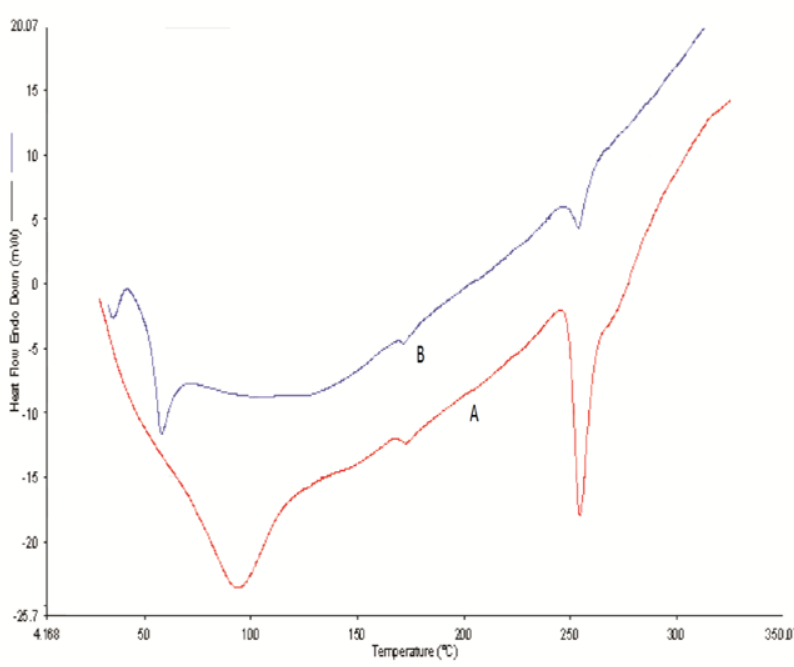

Figure 2: DSC thermogram of the pure drug (Acyclovir) [A] and optimized formulation (F5) [B].

SLN or adsorbed onto the surface. The incorporation of drug into SLN exhibited no effect on the zeta potential values of the nanoparticles. Further, high values of zeta potential can be responsible for a greater electric repulsion. Tween 80 in the formulation provided the steric stability of SLN. ${ }^{20}$

\section{Entrapment efficiency and loading efficiency}

The results of the drug \% EE and \% LE of SLNG formulations are demonstrated in Table 3. All the formulations showed high drug entrapment efficiency ranging from 66.17 to $82 \%$. The formulation F5 showed maximum drug entrapment efficiency of $82 \%$. The drug entrapment efficiency was increased by increasing the concentration of the selected polymer. The $\%$ drug loading efficiency was found to be in the range of 52.2 to $72.01 \%$. The formulation F1 showed a maximum \% LE of $72.01 \%$. Similarly, the loading capacity of nanoparticles decreased as the concentration of polymer increased..$^{21,22}$
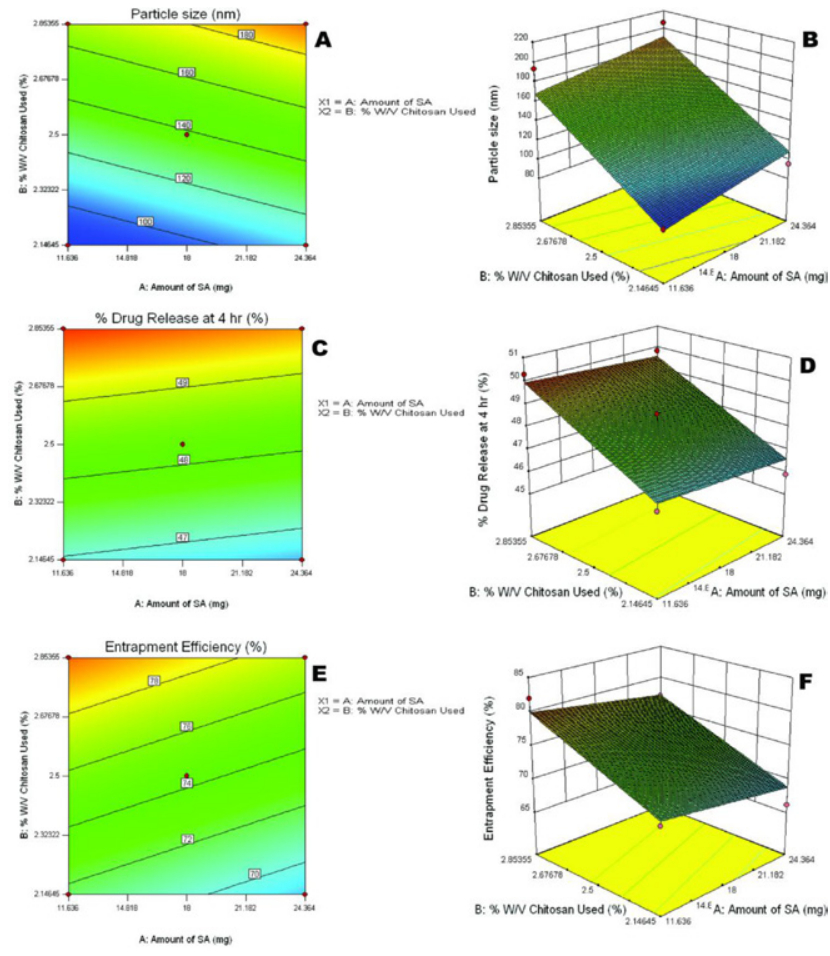

Figure 3: Contour plot A and response surface plot B showing the effect of the ratio of the stearic acid and soya lecithin (X1) and \% w/v chitosan used (X2) on the particle size of the formulation; Contour plot $\mathbf{C}$ and response surface plot $\mathrm{D}$ showing the effect of the ratio of the stearic acid and soya lecithin (X1) and \% w/v chitosan used (X2) on \% of drug release at $4 \mathrm{~h}$ of the formulation; Contour plot $\mathrm{E}$ and response surface plot $F$ showing the effect of the ratio of the stearic acid and soya lecithin (X1) and \% w/v chitosan used (X2) on the entrapment efficiency (\%) of the formulation.

\section{Response surface analysis of particle size}

The contour plot and three-dimensional analysis of the studied response variable, particle size $(\mathrm{nm})$, is represented in Figure 3 (A and B). The graphs showed the effects of the two separate variables, i.e., ratio of stearic acid and soya-lecithin (X1) and \% w/v of chitosan used (X2), on the response variable, i.e., particle size (Y1). From the contour plot, seen that an increase in particle size $(\mathrm{nm})$ with an increase in the ratio of stearic acid and soya lecithin (X1) and \% w/v of chitosan used (X2). Their variables showed the change in a linear and ascending manner as respective to the responses' changes. From the three dimensional graphs, seen that the particle size $(\mathrm{nm})$ increased with an increase in the ratio of stearic acid and soya-lecithin (X1) and \% w/v of chitosan used (X2). Further it may observe that the particle size $(\mathrm{nm})$ increased with an increase in both variables' values. ${ }^{14}$

\section{Response surface analysis of drug release at $4 \mathrm{~h}$}

The contour plot and three-dimensional analysis of the studied response variable, i.e., drug release at $4 \mathrm{~h}$ 
$(\%)$, is represented in Figure $3(\mathrm{C}$ and $\mathrm{D})$. The graphs showed the effects of the two independent variables, i.e., ratio of stearic acid and soya-lecithin (X1) and \% $\mathrm{w} / \mathrm{v}$ of chitosan used (X2), on the response variable, i.e., $\%$ of drug release at $4 \mathrm{~h}(\mathrm{Y} 2)$. The contour plot stated that the $\%$ of drug release at $4 \mathrm{~h}$ increased with an increase in the ratio of stearic acid and soya-lecithin (X1) and \% w/v of chitosan used (X2). The response changes the variables in a linear and ascending manner. From the three-dimensional graph, it concluded that the $\%$ of drug release at $4 \mathrm{~h}$ increased with an increase in the ratio of stearic acid and soya lecithin (X1) and \% $\mathrm{w} / \mathrm{v}$ of chitosan used (X2). It was observed that the $\%$ of drug release at $4 \mathrm{~h}$ increased with an increase in the values of both the variables. The contour plot and three-dimensional analysis of the studied response variable, i.e., drug release at $4 \mathrm{~h}(\%)$, is represented in Figure $3(C$ and $D)$. The graphs showed the effects of the two independent variables, i.e., ratio of stearic acid and soya-lecithin (X1) and \% w/v of chitosan used (X2), on the response variable, i.e., \% of drug release at $4 \mathrm{~h}$ (Y2). From the contour plot, it was stated that the $\%$ of drug release at $4 \mathrm{~h}$ increased with an increase in the ratio of stearic acid and soya-lecithin (X1) and \% $\mathrm{w} / \mathrm{v}$ of chitosan used (X2). The response changes the variables in a linear and ascending manner. From the three-dimensional graph, it was concluded that the $\%$ of drug release at $4 \mathrm{~h}$ increased with an increase in the ratio of stearic acid and soya lecithin (X1) and \% w/v of chitosan used (X2). It was observed that the $\%$ of drug release at $4 \mathrm{~h}$ increased with an increase in the values of both the variables. With increasing concentration of chitosan was diluted by the luminal fluids while progressing through the gastrointestinal tract, probably resulting in insufficiently high concentrations at acyclovir's absorption site. Moreover, the actually dissolved and protonated fraction of chitosan may have been too low at gastrointestinal $\mathrm{pH}$, thereby limiting a charge-based interaction with the epithelial membrane and improved drug release. ${ }^{15}$

\section{Response surface analysis of entrapment efficiency}

The contour plot and three-dimensional analysis of the studied response variable i.e., drug $\% \mathrm{EE}$ is represented in Figure 3 ( $\mathrm{E}$ and $\mathrm{F}$ ). The graphs showed the effects of the two independent variables, i.e., ratio of stearic acid and soya lecithin (X1) and \% w/v of chitosan used (X2), on the response variable, i.e., entrapment efficiency (Y3). From the contour plot, it was concluded that the $\% \mathrm{EE}$ decreased with an increase in the ratio of stearic acid and soya-lecithin (X1) and \% EE increased with an increase in $\% \mathrm{w} / \mathrm{v}$ of chitosan (X2). The response changed the variables in a linear and both in ascending as well as descending manners. From the three-dimensional graph, it was concluded that the $\%$ EE decreased with an increase in the ratio of stearic acid and soya-lecithin (X1) and \% EE increased with increase in $\% \mathrm{w} / \mathrm{v}$ of chitosan (X2). It was concluded that the $\%$ of $\mathrm{w} / \mathrm{v}$ of chitosan improved the $\%$ EE of the formulations. Still, an increase in the ratio of stearic acid and soya-lecithin exhibited a negative effect on the $\%$ EE of the formulations. ${ }^{16}$

\section{Validation of RSM results of acyclovir-loaded SLNG}

Statistical optimization of the selective formulation was done for tuning to get an optimized ratio and obtaining the best-optimized formulation. A $2^{3}$ factorial design was implemented to optimize the formulation attributes such as the ratio of stearic acid and soya-lecithin (X1) and $\% \mathrm{w} / \mathrm{v}$ of chitosan used (X2). Statistical treatments to the particle size (nm), $\%$ of drug release at $4 \mathrm{~h}$ and $\%$ $\mathrm{EE}$ data revealed that the $\mathrm{X} 1$ and $\mathrm{X} 2$ both variables are significant for the formulation. The F5 formulation was chosen as the best-optimized ocular SLNG formulation of acyclovir with stearic acid and chitosan. Observed and predicted data values of linear correlation plots for particle size (nm), \% drug release at $4 \mathrm{~h}$ and $\%$ EE of ocular SLNG of acyclovir showed regression coefficient $\left(R^{2}\right)$ value that is 0.999 with a $\mathrm{Y}$ value of 1.026 at 3.984 intercept for particle size, regression coefficient $\left(R^{2}\right)$ value that is 0.997 with a $\mathrm{Y}$ value of 0.935 at 2.902 intercept for $\%$ drug release at $4 \mathrm{~h}$ and regression coefficient $\left(R^{2}\right)$ value that is 0.991 with a $Y$ value of 0.936 at 4.758 intercept for \% EE respectively. ${ }^{17}$

\section{Characterization of acyclovir-loaded SLNG Physical evaluation}

The appearance of all formulations was off white and was cloudy. The $\mathrm{pH}$ values existed between 7.2 to 7.4 and drug content values were in the range of 77.50 to $89.26 \%$, which indicated that the formulations were desirable for ophthalmic preparations. The $\mathrm{pH}$ of the ocular formulation is directly related to its tolerability. The $\mathrm{pH}$ of the prepared of SLNG laden $\mathrm{pH}$ sensitive in situ gel ranged from 7.2 to 7.4 (Table 3). As the concentration of polymer increased the $\mathrm{pH}$ increased to the more basic side of the scale. Thus, the $\mathrm{pH}$ of the gel was adjusted with $0.1 \mathrm{~N} \mathrm{NaOH}$ till it attained the suitable $\mathrm{pH}$ value which is compatible for ocular use and where it existed in sol state because at $\mathrm{pH} 7.4$ it will be gelled hence for administration purpose it should be in the sol state (Table 3). ${ }^{19,30}$ 


\section{Sterility testing}

After seven days of incubation, the formulation is characterized for sterility and the results showed there was a complete absence of any microbial growth in any formulations (Table 3 ). ${ }^{26}$

\section{Ocular irritancy test}

Male albino rabbits were selected for this study to evaluate the ocular irritancy test for final optimized formulation (F5) as per the Draize technique. The results showed that optimized formulation (F5) exhibited non-irritant activity with no visual damage or abnormal clinical signs and good ocular tolerance. Further, the obtained results of this study depicted in Table $3 .^{27}$

\section{Ex-vivo transcorneal permeation study}

Ex-vivo trans-corneal permeation study performed by selecting goat corneas across the corneal membrane using Franz diffusion cells by maintaining the temperature of $37 \pm 0.5^{\circ} \mathrm{C}$. The UV-Visible spectrophotometric (Shimadzu-1700, Tokyo, Japan) method was used to quantify acyclovir by collecting aliquots at periodical time intervals for up to $4 \mathrm{~h}$ in the pre-weighed micro centrifuge tubes. The data found that the concentration of chitosan polymer played an essential role in increasing the percentage of drug release. The cumulative percentage of drug permeated through the corneal membrane was less as compared to that with a dialysis membrane. The corneal layer act as a mechanical barrier made up of epithelium (lipophilic), stroma (hydrophilic) and endothelium (less lipophilic than epithelium) and also as a lipophilic-hydrophilic barrier for corneal penetration of drug during dialysis membrane because of maximum protein binding of drug. ${ }^{19,27}$

\section{In vitro drug release kinetics and release mechanism}

It was clear that the in vitro drug release profile from the prepared drug-loaded SLNs formulations showed an initial burst release followed by an extended-release of drug. This release profile is typical in matrix based formulations where initial rapid drug release occurs due to solubilization of the adsorbed drug on the surface and time the release rate declines due to controlled by diffusion of the dissolution medium and erosion of the matrix. To determine the kinetics and mechanism of drug release from the optimized batch of SLN fitted into a different release order of kinetics such as zeroorder (Figure 4), first-order and Higuchi order kinetics and from the regression correlation value of different kinetics of formulation F5 showed the optimized batch followed first-order release kinetic $\left(R^{2}=0.998\right) .{ }^{31}$

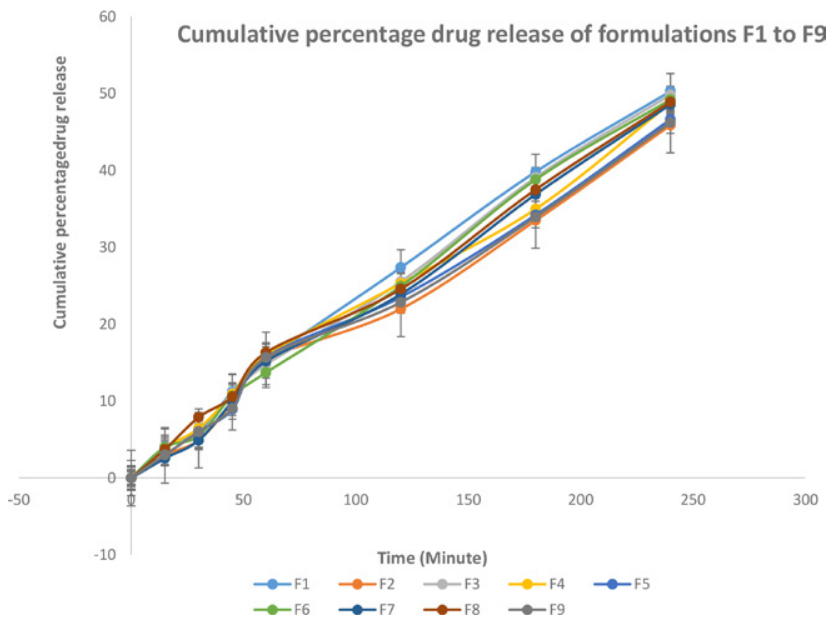

Figure 4: Relative graph showing the cumulative percentage drug release of all the formulations (F1 to F9).

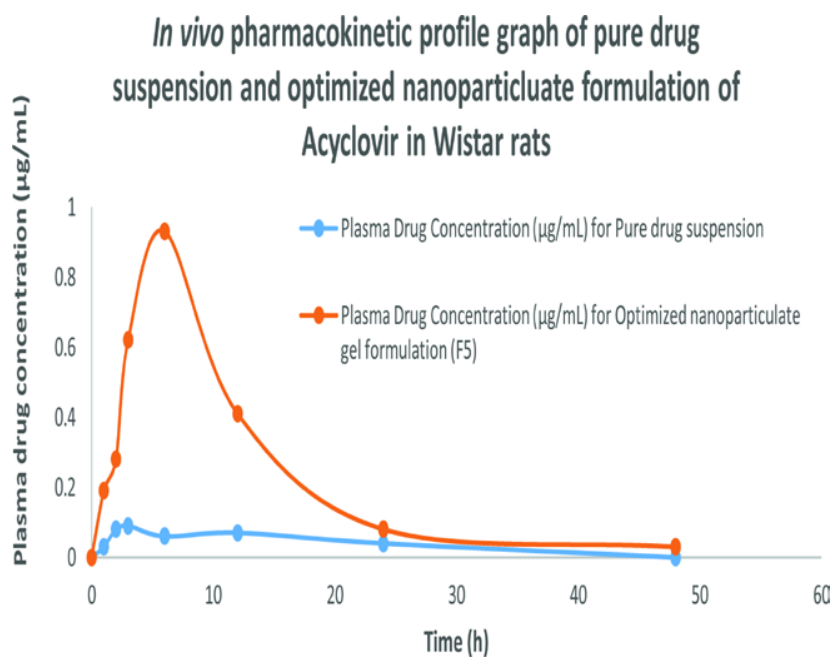

Figure 5: In-vivo pharmacokinetic profile graph of optimized formulation (F5) and pure drug suspension in Wistar rats.

\section{In-vivo pharmacokinetic study}

The plasma drug concentration-time profile showed in Figure 5 for the optimized formulation batch and oral suspension. The optimized SLN formulation clearly showed better enhancement in the pharmacokinetic profile. The mean peak plasma concentration $\left(\mathrm{C}_{\max }\right)$ for solid lipid nanoparticles and pure drug suspension found to be $0.93 \mu \mathrm{g} / \mathrm{mL}$ and $0.06 \mu \mathrm{g} / \mathrm{mL}$. Besides, this solid lipid nanoparticle, in comparison to the pure drug suspension, had significantly increased area under the curve (AUC). However, there was no significant change in time at peak plasma concentration $\left(\mathrm{T}_{\max }\right)$ and remained unchanged. A significant improvement $(p<0.001)$ observed as a result of the drug's systemic bioavailability. The values of $\mathrm{AUC}$ and $\mathrm{C}_{\max }$ of optimized SLN formulation concerning pure drug suspension gave us clear evidence of the effect. ${ }^{32}$ 


\section{Stability study}

As per ICH guidelines, short-term accelerated stability studies for three months $\left(40 \pm 2^{\circ} \mathrm{C}\right.$ and $\left.75 \pm 5 \% \mathrm{RH}\right)$ for optimized formulation (F5) was performed by keeping the formulation in ambient colored vials and sealed with aluminum foil. The results showed excellent physical stability without change of clarity and phase separation or absence of drug degradation during the stability condition. The smaller size of the particles and the steric effect of tween 80 and carbopol 940P are the primary concerns about the formulation's excellent stability. The formulation containing lipids may take place slow recrystallization during the manufacturing process is the reason for the constant particle size of optimized batch during storage condition. As a general, it was evident that there was an insignificant change in clarity and zeta potential, as well as particle size values at specific time intervals of the study, indicated the stability of the formulation. ${ }^{19,29}$

\section{CONCLUSION}

The present study demonstrated that the 23 factorial design employed in developing solid lipid nanoparticle gel (SLNG) of acyclovir prepared by hot homogenization technique. The optimized formulation showed a particle size of $193.57 \pm 1.14 \mathrm{~nm}$, the zeta potential of $35 \pm 1.98 \mathrm{mv}$, drug entrapment efficiency of $82 \pm 1.59 \%$ and drug loading efficiency of $54.10 \pm 0.79 \%$ of SLNG showed that the formulation F5 was the optimized batch. It contained soya-lecithin and stearic acid, suitable lipids, chitosan as a rate-controlling polymer and tween80 as a surfactant. It is seen that acyclovir SLN gel can be developed and optimized with enhanced entrapment efficiency and controlled particle size. And this optimized formulation will be an alternative drug delivery system for drug to enhance systemic bioavailability and show excellent physical stability with better therapeutic responses. The present study supported significant enhancement in the biopharmaceutical features of acyclovir from optimized SLNG, which can effectively used for treating ocular viral infections. Therefore, the gel-based SLN formulation of acyclovir is a choice for single drug administration as it overcomes the limitations associated with oral dosage administration of acyclovir. The optimized formulation found to be non-irritant and safe for topical ophthalmic use. Thus, as mentioned above, the technique could significantly help to overcome the issues associated with acyclovir.

\section{Ethical Issues}

All the animal studies performed in the present work were carry-out upon the approval of the study protocol (Registration number: 2075/PO/Re/s/19/CPCSEA) from the Calcutta Institute of Pharmaceutical Technology and Allied Health Sciences, West Bengal, India. All the studies were carry-out as per the guidelines of the Committee for Control and Supervision of Experiments on Animals (CPCSEA), Government of India.

\section{ACKNOWLEDGEMENT}

The authors appreciate and acknowledge the immense support of the Management of SIMS College of Pharmacy, Guntur (Andhra Pradesh, India) and the Calcutta Institute of Pharmaceutical Technology and Allied Health Sciences (West Bengal, India) thanks for the facilities provided during the research work.

\section{CONFLICT OF INTEREST}

The author declares there is no any conflict of interest in preparing the manuscript.

\section{ABBREVIATIONS}

2D: Two dimensional; 3D: Three-dimensional; ANOVA: Analysis of variance; AUC: Area under the curve; $\mathbf{C}_{\text {max }}$ : Mean peak plasma concentration; DSC: Differential scanning calorimetry; EE: Entrapment efficiency; FT-IR: Fourier transform infrared spectroscopy; ICH: International Conference on the Harmonization; MLRA: Multiple linear regression analysis; PDI: Polydispersibility index; $\boldsymbol{R}^{2}$ : Regression coefficient; RSM: Response surface methodology; SLN: Solid lipid nanoparticles; SLNG: Solid lipid nanoparticulate gel; $\mathbf{T}_{\text {max }}:$ Peak plasma concentration; UV: Ultra-violet.

\section{REFERENCES}

1. De S, Robinson D. Polymer relationships during preparation of chitosanalginate and poly-L-lysine-alginate nanospheres. J Control Rel. 2003;89(1):101-12. https://doi.org/10.1016/S0168-3659(03)00098-1.

2. Gupta S, Kesarla R, Chotai N, Misra A, Omri A. Systematic Approach for the Formulation and Optimization of Solid Lipid Nanoparticles of Efavirenz by High Pressure Homogenization using Design of Experiments for Brain Targeting and Enhanced Bioavailability. Biomed Res Int. 2017;5984014. doi:10.1155/2017/5984014

3. Hussain A, Singh S, Das SS, Anjireddy K, Karpagam S, Shakeel F. Nanomedicines as drug delivery carriers of anti-tubercular drugs: from pathogenesis to infection control. Curr Drug Deliv. 2019;16(5):400-29. doi: 10 .2174/1567201816666190201144815.

4. Alonso MJ. Nanomedicines for overcoming biological barriers. Biomed Pharmacoth. 2004; 58:168-72. DOI: 10.1016/j.biopha.2004.01.007.

5. Lang JC. Ocular drug delivery conventional ocular formulations. Adv Drug Deliv Rev. 1995; 16:39-43. https://doi.org/10.1016/0169-409X(95)00012-V. 
6. Le CB, Acar L, Zia H, Sado PA, Needham T, Leverge R. Ophthalmic drug delivery systems: Recent advances. Prog Retinal Eye Res. 1998; 17:33-58. DOI:10.1016/s1350-9462(97)00002-5.

7. Smolin G, Okumoto M, Feiler S, Condon D. Idoxuridine-liposome therapy for herpes simplex keratitis. Am J Ophthalmol. 1981;91(2):220-5. doi: 10.1016/0002-9394(81)90177-x.

8. Losa C, Calvo P, Castro E, Vila-Jato JL, Alonso MJ. Improvement of ocular penetration of amikacin sulphate by association to poly-(butylcyanoacrylate) nanoparticles. J Pharm Pharmacol. 1991;43(8):548-52. doi: 10.1111/j.20427158. 1991.tb03534. $x$.

9. Losa C, Marchal-Heussler L, Orallo F, Vila-Jato JL, Alonso MJ. Design of new formulations for topical ocular administration: Polymeric nanocapsules containing metipranolol. Pharm Res. 1993;10(1):80-7. doi: 10.1023/a:1018977130559.

10. Gambhire VM, Gambhire MS, Ranpise NS. Solid lipid nanoparticles of dronedarone hydrochloride for oral delivery: optimization, in vivo pharmacokinetics and uptake studies. Pharm Nanotechnol. 2019;7(5):37588. doi: $10.2174 / 2211738507666190802140607$.

11. Nagi AA, Abdullah RSI, Ahmad B. Tamoxifen drug loading solid lipid nanoparticles prepared by hot high-pressure homogenization techniques. Am J Pharmacol Toxicol. 2008;3(3):219-24.

12. Shrivastava AR, Ursekar B, Kapadia CJ. Design, optimization, preparation and evaluation of dispersion granules of valsartan and formulation into tablets. Current Drug Deli. 2009;6(1):28-37. doi: 10.2174/156720109787048258.

13. Ismail $A A$, Sanaa $A E$, Medhat $A F$,Ahmed MD. Influence of a niosomal formulation on the oral bioavailability of acyclovir in rabbits. AAPS Pharm Sci Tech. 2007 ;8(4):206-12. doi: 10.1208/pt0804106.

14. Brahmaiah B, Varun D, Vijay K, Swain S, Beg S. Quality-by-Design based development and characterization of pioglitazone loaded liquisolid compact tablets with improved biopharmaceutical attributes. J Drug Deli Sci Tech. 2019;51:345-55. https://doi.org/10.1016/j.jddst.2019.03.033.

15. Kubbinga M, Nguyen MA, Staubach $P$, et al. The Influence of chitosan on the oral bioavailability of acyclovir-a comparative bioavailability study in humans. Pharm Res. 2015;32(7):2241-9. https://doi.org/10.1007/s11095-014-1613-y.

16. Someshwar K, Swain S, Rao MEB, Jena BR, Vishali D. QbD-based design and characterization of mucoadhesive microspheres of quetiapine fumarate with improved oral bioavailability and brain biodistribution potential. Bulletin of Faculty of Pharmacy, Cairo University. 2018;56(2):129-45. https://doi. org/10.1016/j.bfopcu.2018.09.002.

17. Swain S, Sruti J, Patra CN, Beg S, Rao MEB, Dinda SC. Formulation design, optimization. Characterization and in vivo pharmacodynamics study of enteric coated mucoadhesive microcapsules of esomeprazole magnesium. Drug Deliv Letters. 2015;5(2):86-99. DOI: 10.2174/2210303105666150619152450.

18. Rajendran NN, Natrajan R, Siva KR, Selvaraj S. Acyclovir-loaded chitosan nanoparticles for ocular delivery. Asi J Pharm. 2010;4(4):220-6. DOI: http:// dx.doi.org/10.22377/ajp.v4i4.290.

19. Sanaa AE, Gamal ME, Asmaa AH. Formulation of acyclovir-loaded solid lipid nanoparticles: design, optimization and in-vitro characterization.
Pharmaceutical Development and Technology. 2019;24(10):1287-98. DOI: $10.1080 / 10837450.2019 .1667385$.

20. Jenning V, Gysler A, Schafer-Korting M, Gohla SH. Vitamin a loaded solid lipid nanoparticle for topical use: occlusive properties and drug targeting to the upper skin. Eur J Pharm Biopharm. 2000;49(3):211-8. DOI: 10.1016/ S0939-6411(99)00075-2.

21. Angela C, Yolanda D, Edison LSC, Alejandro S, Maria JA. Chitosan nanoparticles as new ocular drug delivery systems: In-vitro stability, in vivo fate and cellular toxicity. Pharm Res. 2004;21(5):803-10. https://doi. org/10.1023/B:PHAM.0000026432.75781.cb.

22. Swain S, Behera A, Dinda SC, Patra CN, Jammula S, Beg S, et al. Formulation design, optimization and pharmacodynamic evaluation of sustained release mucoadhesive microcapsules of venlafaxine $\mathrm{HCl}$. Indian J Pharm Sci. 2004;21(5):803-10.

23. Rao MEB, Swain S, Patra CN, Mund SP. Formulation design, optimization and characterization of eprosartan mesylate nanoparticles. Nanosci NanotechAsia. 2018;8(1):130-43. DOI: 10.2174/2210681206666160822121922.

24. Ali S, Raida AK. Development of solid lipid nanoparticles and nanostructured lipid carriers for improving ocular delivery of Acyclovir. Drug Dev Ind Pharm. 2013; 39:508-19. DOI: 10.3109/03639045.2012.665460.

25. Rajasekaran A, Sivakumar V, Karthika K, Preetha JP, Abirami T. Design and evaluation of polymeric controlled release natamycin ocular inserts. Kathmandu University J Sci Eng Tech. 2010; 6:108-15. DOI: 10.3126/kuset. v6i1.3318.

26. Hussein OA, Salama HA, Ghorab M, Mahmoud AA. Nanoemulsion as a potential ophthalmic delivery system for dorzolamide hydrochloride. AAPS PharmSci Tech. 2009; 10:808-18. doi: 10.1208/s12249-009-9268-4.

27. Zhidong L, Xinhua Z, Haoyun W, Jiawei L, Lexin S, Rui L, Lin L, Nan L. Preparation and evaluation of solid lipid nanoparticles of baicalin for ocular drug delivery system in vitro and in vivo. Drug Development and Industrial Pharmacy, 2011, 37(4): 475-481. DOI:10.3109/03639045.2010.522193.

28. Ankit AK, Akhlesh KS. Reverse Phase High Performance Liquid Chromatography Method for Quantification of Acyclovir in Rat Plasma. Drug Deli Letters. 2013; 3:233-8. 10.2174/22103031113039990009.

29. Beg S, Swain S, Singh HP, Patra CN, Rao MEB. Development, optimization and characterization of solid self-nanoemulsifying drug delivery systems of valsartan using porous carriers. AAPS Pharm SciTech. 2012; 13:1416-27. doi: 10.1208/s12249-012-9865-5.

30. Law SL, Huanq KJ, Chianq $\mathrm{CH}$. Acyclovir -containing liposomes for potential ocular delivery, corneal penetration and absorption. J Control Release. 2000; 63:135-140. https://doi.org/10.1016/0168-3659(90)90122-A.

31. Khames A. Preparation and characterization of sildenafil loaded solid lipid nanoparticles: Drug delivery system suitable for nebulization. 2017; Pharm Lett. 9:98-112.

32. Claudia G, Claudio B, Adriana M, Donatella P, Maria AV, Giovanni P, Vincent $\mathrm{HL}$, LeeMassimo F. Influence of preparation conditions on Acyclovir-loaded poly-d, I-lactic acid nanospheres and effect of PEG coating on ocular drug bioavailability. Pharm Res. 2003; 20:584-9. DOI: 10.1023/a:1023290514575.

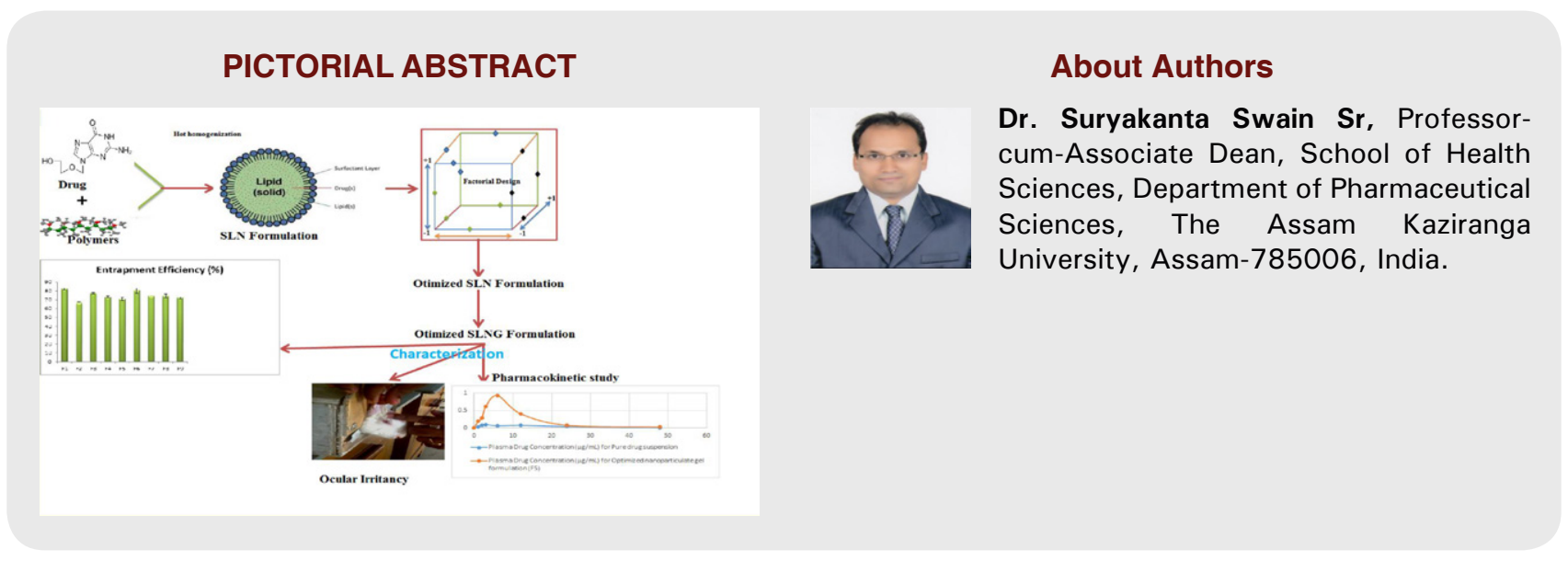




\section{SUMMARY}

- The study involved the development of factorial design-based solid lipid nanoparticulate gel formulation by hot homogenization technique, optimization and characterization to achieve enhanced systemic bioavailability and efficacy of the drug.

- Acyclovir based nano lipid carriers were optimized by factorial design with possible minimum nano-size range and high drug entrapment and drug loading efficiency.

- Ex-vivo transcorneal permeation and ocular irritation studies of optimized formulation batch of acyclovir solid lipid nanoparticulate gel showed improved ocular delivery and permeability rate of the drug.

- In vivo animal pharmacokinetics study on the Wistar Rat model revealed great promising oral bioavailability potential of the optimized drug-loaded SLNG compared to the pure drug suspension.

- The research focused on sterility testing and accelerated stability testing for the optimized formulation of acyclovir solid lipid nanoparticulate gel for drug formulation stability.

Cite this article: Majumdar S, Swain S, Rao MEB, Chakraborty P, Das S. Acyclovir Loaded Solid Lipid Nanoparticulate Gel for Ocular Delivery: Optimization by using Factorial Design. Indian J of Pharmaceutical Education and Research. $2021 ; 55(1 s): s 122-s 134$. 